\title{
SOBRE AS RUPTURAS DE UM DISCURSO UNIVERSAL DE DIREITOS HUMANOS DIANTE DE UMA CRIMINOLOGIA DECOLONIAL FEMINISTA NOS CRIMES RELACIONADOS A DROGAS
}

\section{ON THE BREAKS OF A UNIVERSAL ADDRESS HUMAN RIGHTS BEFORE AN CRIMINOLOGY DECOLONIAL FEMINIST IN RELATED CRIMES DRUG}

\author{
${ }^{1}$ Bruna Stéfanni Soares de Araújo \\ ${ }^{2}$ Maria Luiza Caxias Albano
}

\section{RESUMO}

Diante da necessidade de uma concepção feminista decolonial e contra-hegêmonica para a criminologia crítica e criminologia feminista que abordam as questões referentes aos crimes relacionados a drogas e a criminalização das mulheres na América Latina, subsiste o questionamento de um discurso uníssono a respeito dos Direitos Humanos. Portanto, o presente trabalho pretende analisar a complexidade que envolve o discurso universal de direitos humanos, a situação de mulheres latinoamericanas nos crimes relacionados às drogas e as possibilidades epistemológicas insurgentes, utilizando para tanto a revisão bibliográfica e os dados de pesquisas realizadas por órgãos oficiais.

Palavras-chave: Estudos decoloniais, Feminismo latinoamericano, Criminologia, Direitos humanos, Política criminal

\begin{abstract}
Given the need for decolonial feminist design and counterhegemonic for critical criminology and feminist criminology that address issues related to drug-related crimes and the criminalization of women in Latin America, there remains the question of a unison discourse on Human Rights. Therefore, this study aims to analyze the complexity that involves the universal discourse of humanso rights, the situation of Latin American women in drugrelated crimes and the epistemological possibilities insurgents, using both the literature review and survey data by official bodies.
\end{abstract}

Keywords: Studies decolonized, feminism latinoamerican, Criminology, Human rights, Criminal policy

\footnotetext{
${ }^{1}$ Mestranda em Ciências Jurídicas pela Universidade Federal da Paraíba - UFPB, João Pessoa - PB (Brasil). E-mail: brunastefannis1@gmail.com

${ }^{2}$ Mestranda em Ciências Jurídicas na Universidade Federal da Paraíba - UFPB, João Pessoa - PB (Brasil).

E-mail: marialuiza.caxias@gmail.com
} 


\section{INTRODUÇÃO}

É comum dividir a história do feminismo em várias ondas, como se fossem estágios do processo de construção da igualdade entre os gêneros. De acordo com essa divisão, a primeira onda, se destacou pela luta das mulheres europeias e norte americanas pelo direito ao voto e participação política, identificando tais mobilizações como os primeiros passos do feminismo, tal qual a luta das mulheres organizadas contra as formas de opressão masculina, na história. Ora, tal concepção reforça uma ideia de mundo que tem como centro de referência política e social a Europa e os Países do Norte, e que invisibiliza muitas formas de resistência contra o patricardo nos diversos momentos da humanidade e em diferentes lugares. Anibal Quijano identifica tal comportamento de colocar a Europa e os demais "Países do Norte" como centrais na formação da modernidade e padrão de civilização como la colonialidad del Poder (Quijano, 2000, p. 217), que impactou e influenciou as teorias feministas, assim como vários outros campos do conhecimento, desde então.

Tal lógica levada a cabo pelo capitalismo e colonialismo, engendra uma hegemonia de produção e supervalorização de saberes, que se desenvolvem em meio ao silenciamento e exclusão de outras culturas e vivências, é portanto um sistema de dominação epistemológica, em que há a desqualificação e desconsideração das muitas formas de saber e conhecimentos dos povos colonizados colocando-os num espaço de subalternidade.

É também nesse contexto que o dircurso de Direitos Humanos aparece: de um lado, a linguagem dos direitos humanos se propagou enquanto uníssona e normativa de códigos morais considerados universais, reconhecidos atualmente por diversas ideologias políticas enquanto conteúdo fundamental de uma ideia de justiça (ATIENZA, 2012, p. 34), por outro, representa simbolicamente um discurso colonizador e limitado a partir de contextos específicos. Assim, é necessário ampliar a discussão e problematização das várias formas de compreensão dos direitos humanos em consonância com as várias realidades existentes, no caso, mais especificamente, a realidade da mulher latinoamericana em casos de crimes relacionados a drogas.

Levando em consideração a imperatividade do reconhecimento de feminismos diversos e que melhor dão conta das diferentes construções históricas do que é ser mulher, urge a feitura de uma teoria feminista, para além dos discursos universalistas de direitos humanos, que abarque os elementos peculiares da mulher latino americana, caribenha e negra, assim, e utilizar essas óticas contra-hegêmonicas para observação dos fenômenos sociais relativos a elas na América Latina. Entre esses fenômenos, destacamos o fenômeno da 
criminalização, em especial, os crimes relacionados às drogas, que serão melhor analisados posteriormente nesse trabalho.

Dessa forma, analisa-se a necessidade de um deslocamento epistemológico acerca do feminismo que fundamenta as reflexões em torno da criminologia feminista e seus estudos em sede de América Latina, como essencial para a compreensão dos fenômenos sociais aqui presentes. Para tal, será utilizada a pesquisa e revisão bibliográfica, juntanente com a coleta de dados disponibilizados por órgãos oficiais.

\section{A CONSTRUÇÃO DE UM DISCURSO UNIVERSAL DE DIREITOS HUMANOS: O RELATO DO VENCEDOR NA FORMAÇÃO DE UMA HEGEMONIA}

Dentro da conjuntura de formação do paradigma de modernidade, observou-se a emergência do capitalismo mercantilista (primeira fase), do indivíduo-cidadão e das nacionalidades constituídas por cidadãos de múltiplas origens étnicas e linguísticas, o que compelia, de algum modo, os dirigentes da ordem burguesa pós-revolucionária, vencedores das revoluções burguesas, a uma estratégia de unificação da linguagem e dos valores axiológicos/éticos (ABREU, 2008, p. 118). Assim, por ser fruto da modernidade, a ideia inicial de direitos humanos foi edificada por meio de paradigmas que, com pretensões de universalidade e veracidade absoluta, puseram-se como formas superiores de pensamento e justificação: através do jusnaturalismo racional $^{1}$ (e/ou direito natural laicizado), a razão se torna a linguagem do poder. Acredita-se/acreditou-se que através de processos racionais (e da produção de ciência) haveria como se atingir a verdade, o conhecimento, e porque não, a revelação do que é justo e correto moralmente?

Se por um lado a preocupação da modernidade foi na estabilização desses elementos político-sociais (valores, língua, cultura) a partir da construção de discursos que legitimavam a própria produção epistemológica enquanto unívoca e verídica (científica), por outro, o jusnaturalismo moderno/racional foi responsável por elaborar a ideia de direitos inatos, tidos como verdades evidentes, os "direitos do homem" ou "humanos", que seriam a medida

\footnotetext{
1 Em relação ao Direito Natural racional, Ernst Bloch tece algumas considerações: "La deduccion ininterrumpida desde unos princípios distingue al Derecho natural racionalista, de modo principal, de la desintegracion y concatenacion de conceptos, agudas, pero carentes de critério unitário (...). El método del continuo ratiocinationes filo deducere convirtió entonces al Derecho natural junto a la matematica y casi con su mismo prestigio, en el ideal de una ciencia demostrativa." Continua: "...triunfaba entonces la fe en una generalidad en la que todas las determinaciones son homogéneas y constantes: en la idea niveladora de la naturaleza mecánica.” (BLOCH, Ernst. 2011. p. 133)
} 
valorativa/moral da comunidade política, mas que dela (de maneira ideal) independeriam. Logo, a positivação das Declarações de Direitos Humanos teria uma utilidade basilar na estruturação da sociedade moderna, determinando, de modo a se tornar inquestionável ${ }^{2}$, os valores éticos que regeriam a organização político-econômica então estabelecida. Nessa acepção:

\begin{abstract}
(...) a positivação das Declarações de Direitos Humanos, nas constituições, tinha como objetivo conferir segurança aos direitos nelas contemplados, para tornar aceitável pela sociedade a variabilidade do Direito Positivo, requerida pelas necessidades da gestão do mundo moderno (LAFER, 1988, p. 21).
\end{abstract}

Desse modo, os direitos humanos, dentro de uma perspectiva jurídica, tende a proteger um mundo construído (paradigma moderno) no qual a hegemonia (e por isso a "legitimação" em constituir o modelo organizativo) deve permanecer sempre dentro dos parâmetros daqueles que foram os responsáveis por estrutura-lo, os vencedores. Nesse aspecto, Michel Villey aponta que as Declarações/Convenções de direitos humanos/do homem proclamadas desde 1776, nos Estados Unidos da América até as mais recentes, passando pela Declaração Universal das Nações Unidas de 1948, funcionaram como uma arma defensiva:

Elas foram, repito, uma arma defensiva; em 1789, contra o pretenso absolutismo da monarquia capetiana (não é seguro que ela merecesse esse qualificativo); ou, em 1948, contra o fantasma de Hitler: contra as ditaduras de todos os tipos. Geralmente, um remédio para a desumanidade de um direito que rompeu suas amarras com a justiça. (...) Em toda a parte, a insuficiência das leis. Os direitos humanos seriam o recurso (VILLEY, 2007, p.4)

Acontece que, não por acaso ou coincidência, os eventos elencados por Villey, expostos anteriormente enquanto marcos de Declarações de Direitos Humanos, estão relacionados a trocas de poder na esfera política de sociedades ocidentais consideradas atualmente "desenvolvidas", no "centro do mundo". Nesse sentindo, trata-se também do imperialismo ocidental que o discurso dos direitos humanos pode representar frente a outras culturas não-ocidentais. Colocar os valores da cultura ocidental, mistificados enquanto absolutos sob a forma de "direitos humanos", enquanto superiores e neutros e, portanto, obrigatoriamente necessários à aceitação de outras coletividades que não a ocidental é um processo de colonização. É o relato dos vencedores. Dominação travestida de "boas intenções" ocidentais. Para haver um diálogo, seria necessária, primeiramente, a consideração

\footnotetext{
2 Tornam-se inquestionáveis pelo próprio processo que a positivação coloca: os valores ali estabelecidos foram atingidos por meio de processos racionais, paradigma máximo da modernidade.
} 
de paridade de forças entre as diversas culturas existentes - um olhar cuidadoso sobre "o outro", o que, de fato, torna-se praticamente inexistente diante dos pressupostos valorativos racionais modernos que, se um dia foram impostos através dos oceanos, hoje estão nas redes e conexões que os processos de "globalização" impõem.

Diante do exposto, destaca-se mais uma vez que os direitos humanos são positivados dentro dos próprios limites de sua vinculação histórica ao modelo de produção capitalista, ocidental e colonizador, como salientam teóricos marxistas. Destarte, Haroldo de Abreu afirma:

\begin{abstract}
A vida, a liberdade e a propriedade possuídas privadamente pelos indivíduos (abstratamente atomizados e arbitrariamente automizáveis das carências, das condições histórico-sociais e da humanidade que permanece muda) assumem a forma intelectual e moral de 'direitos humanos'. (ABREU, 2008, p. 47)
\end{abstract}

Isso demonstra a artificialidade do discurso dos direitos humanos tradicionalmente desenvolvidos. Artificialidade essa que, conforme Lynn Hunt, já se demonstrava quando aqueles que com tanta confiança declaravam no final do século XVIII que os direitos do homem eram universais tinham algo muito menos inclusivo em mente como referência de humano (HUNT, 2009, p. 16). Assim:

\begin{abstract}
Não ficamos surpresos por eles considerarem que as crianças, os insanos, os prisioneiros ou os estrangeiros eram incapazes ou indignos de plena participação no processo político, pois pensamos da mesma maneira. Mas eles também excluíam aqueles sem propriedade, os escravos, os negros livres, em alguns casos as minorias religiosas e, sempre e por toda parte, as mulheres (HUNT, 2009, p. 17)
\end{abstract}

Observa-se, portanto, que a formação dos direitos humanos, por estar vinculada a uma ideia histórica de estruturação social, bem como a ascensão de formas organizacionais específicas, associa-se a um grupo hegemônico (vencedores da revolução) a fim de proporcionar a segurança jurídica (estabilidade) na perpetuação das estruturas a serem estabelecidas. Desconsidera-se, portanto, ou concebe de forma inferior outras coletividades enquanto não "tão" dignas de humanidade. O processo de desumanização, portanto, o qual os direitos humanos tentam encobrir através dos discursos de universalização, inicia-se na sua própria gênese. Proclamam-se os direitos humanos, pretensiosamente universais e absolutos, mas os humanos dos direitos humanos são apenas aqueles que a estrutura socioeconômica admite como tal. 


\title{
3 AO VENCEDOR, AS BATATAS ${ }^{3}$ : PROCESSOS DE DESUMANIZAÇÃO NA AMÉRICA LATINA, DA COLONIZAÇÃo À POLÍTICA CRIMINAL DE DROGAS
}

$\mathrm{Na}$ construção histórica da América Latina, os processos de desumanização estiveram em curso desde o desembarcar das primeiras caravelas europeias. Assim, ideologicamente, os habitantes das Américas eram considerados sub-humanos aos olhos de seus "conquistadores":

Era, portanto, a desumanização ideológica das vítimas que permitia aos europeus, em plena fase do humanismo renascentista, equiparar a animais os indígenas de nosso continente e os africanos trazidos de terras transatlânticas, ou já nascidos no Novo Mundo (ALVES, 2013, p. 6)

Esses processos de desumanização se perpetuam e, contemporaneamente, assumem formas e roupagens diversas, mas permanecem enquanto marca estrutural da sociedade . Nesse sentido, Luciano Oliveira destaca que a "desumanização" é um dos pontos cruciais para se compreender, em países "periféricos”, a exclusão social, que ganhou novos contornos a partir de meados da década de 80. Assim, destaca a existência de dois traços primordiais (para além de outros) na formulação do fenômeno da exclusão social: o primeiro estaria relacionado ao fato de que excluídos socialmente, postos à margem do processo produtivo e do circuito econômico tradicioal, são considerados "desnecessários”, enquanto que o segundo seria o próprio processo de desumanização:

\begin{abstract}
O segundo traço, aquele que mais imprime força e sentido à própria ideia de exclusão, tem a ver com o fato de que sobre eles se abate um estigma, cuja consequência mais dramática seria a sua expulsão da própria 'órbita da humanidade', isso na medida em que os excluídos, levando muitas vezes uma vida considerada subumana em relação aos padrões normais de sociabilidade, 'passam a ser percebidos como indivíduos socialmente ameaçantes e, por isso mesmo, passíveis de serem eliminados'. (OLIVEIRA, 1997, p. 51)
\end{abstract}

Desse modo, a mesma lógica criminalizadora e estigmatizante que foi iniciada na colonização dos territórios é continuada nas sociedades-latinoamericanas, há uma histórica tradição do extermínio como tecnologia punitiva e mecanismo de controle social, os corpos, sobretudo de pobres e mestiços, indígenas e negros (antes das tribos, campos e senzalas, e depois das favelas), das marginalizadas e conflitivas periferias urbanas ou zonas rurais (ANDRADE, 2012 p. 107) continuam como alvos da seletividade penal.

\footnotetext{
${ }^{3}$ O termo faz alusão à obra de Machado de Assis, "Quincas Borba", onde a frase está relacionada, de forma irônica, à necessidade de se premiar o triunfo de uma coletividade que conseguiria, em um momento de conflito, vencer outra.
} 
É necessário observar, portanto, e de forma específica, como a Guerra às Drogas tem atingidos os diferentes sujeitos que estão envolvidos, ou melhor, que são atingidos por ela. Para além de uma guerra que visa combater a circulação de determinadas substâncias tidas como ilegais, a Política Criminal que visa coibir o uso, consumo e distribuição de entorpecentes atingem pessoas que estão envolvidas nesse cenário. Atingem mais as pessoas do que propriamente os objetos ilícitos perseguidos.

Maierovich (2005, p. 23), indica um dado alarmante, conforme publicado na revista Carta Capital:

\begin{abstract}
os lucros decorrentes do tráfico no mundo alcançaram US\$ 322 bilhões em 2004, segundo as estimativas oficiais da ONU. Na América Latina, foi detectado pelo World Drug Report de 2005 um aumento na produção de cocaína no Peru e na Bolívia, o que demonstra o fracasso da política norte- americana com relação ao controle da produção da droga, especialmente da cocaína. A tentativa de erradicação das plantações de coca na Colômbia (Plan Colômbia), terminou em fracasso e consumiu US\$ 5 bilhões, sem ter sido reduzida a superfície cultivada, que há vinte anos continua com a mesma área de cultivo de 200 mil hectares.
\end{abstract}

Nesse sentido, a repressão por meio de políticas criminalizantes ao fenômeno do consumo e distribuição de drogas ilícitas, além de não ter diminuído sua circulação e uso, e despejar dinheiro público numa empreitada que acaba por ser uma mera enxugadora de gelo, também promove o agravamento da exclusão social daqueles que já estão marginalizados pelas políticas públicas.

Em meio a esse panorama, no século XXI, na América Latina, observa-se o incremento de mulheres presas por delitos relacionados às drogas, como visto, em concomitância ao progressivo endurecimento de leis a estes delitos. De acordo com Giacomello (2013, p. 96):

Entre os anos de 2003-2004, as mulheres presas por crimes relacionados às drogas representavam $47 \%$ da população penitenciária total na Colômbia; $66 \%$ na Costa Rica; $46 \%$ em El Salvador, 26\% na Guatemala, 59\% em Honduras, $89 \%$ na Nicarágua, $72 \%$ no Panamá (Núnez, 2009: 232). Na Venezuela, a partir dos anos 90, mais de $70 \%$ das mulheres privadas de liberdade estão relacionadas a delitos de drogas.

No Equador, 38,2\% das mulheres estavam presas por delitos relacionados às drogas em 1980, ao passo que nos anos recentes, esta porcentagem é de 75\%-80\%, indicando, portanto, um aumento de aproximadamente 40\% (Torres Angarita, 2007, p. 13).

Especificamente sobre a população de mulheres presas no Brasil, que constitui cerca de 6,6\% da população total, a política repressiva contra as drogas apresenta danos consideráveis, assim como na maioria de países latinos, o aumento proporcionalmente em relação aos 
homens presos foi superior: em 2006, 11.000 mulheres estavam presas no Brasil, já em 2012 este número passa para 35.039, ou seja, quase triplica (DEPEN, 2012).

A análise da situação das mulheres criminalizadas pelo delito de tráfico de drogas, que possuem uma participação ainda mais subalterna, conforme diversos estudos indicam, demonstra não só uma marginalização social, mas também de gênero. Segundo relatório do PNUD (1995, p. 43): “a pobreza tem o rosto de uma mulher - de 1.3 bilhão de pessoas pobres, $70 \%$ são mulheres.

Os impactos do proibicionismo são muito nítidos quando trata de sua relação com as mulheres, que constituem uma população vulnerável mesmo hoje com alguns avanços em matérias de igualdade de direitos, o encarceramento massivo que se verifica, que segue atrelado a exclusão social, a famílias divididas e crianças abandonadas, já que as mulheres ainda são as principais responsáveis pela criação de filhos, gera abandono e outras mazelas sociais decorrentes do aprisionamento de mulheres que são as provedoras da casa.

As próprias bases politico-economicas fundadoras da sociedade contemporânea e a construção do Estado brasileiro têm suas raízes no modelo patriarcal, escravocrata e patrimonialista. $\mathrm{O}$ reconhecimento dos direitos das mulheres, da população afrodescendente e da indígena em normas garantidoras é muito recente, a igualdade formal defendida pelas constituições ainda não tem eficácia plena. Há uma forte necessidade de enxergar os sujeitos criminalizados dentro dos lugares sociais que ocupam, nesse caso, mostrou-se imprescindível relacionar a categoria gênero e raça visto que se mostram indissociáveis e a depender da identidade assumida, propensas à exclusão social de políticas públicas e à pinça da seletividade penal.

Portanto, o mercado clandestino de entorpecentes se aproveita do papel social que a mulher carrega, em sua grande maioria, não-branca, moradora da periferia e de áreas marginalizadas da cidade, e agrava sua situação de vulnerabilidade. Na América Latina, os planos de ajustes, flexibilização e liberalização dos direitos sociais provocados pelas políticas neoliberais vitimizara principalmente as mulheres latino americanas.

A história da mulher latino americana e negra e suas situações sociais, são pouco discutidas e silenciadas nos registros históricos e estudos acadêmicos, devido não fazer parte do eixo eurocêntrico de atenções. destaca Ochy Curiel (2009, p. 3): 


\begin{abstract}
A descolonização para nós mulheres se trata de uma posição política que atravessa o pensamento e a ação individual e coletiva, nossos imaginários, nossos corpos, nossas sexualidades, nossas formas de atuar e de ser no mundo e que cria uma espécie de "insurgência antiracista" intelectual, de práticas sociais e da construção de pensamento próprio de acordo a experiências concretas. Se trata do questionamento do sujeito único, ao eurocentrismo, ao ocidentalismo, a colonialidade do poder, ao tempo que reconhece propostas como a hibridação, a polisemia, o pensamento-outro, subalterno e fronteiriço. Estas propostas críticas do feminismo latinoamericano e caribenho são posições de oposição ao feminismo ilustrado, branco, heterossexual, institucional e estatal, mas sobre todo um feminismo que se pensa e repensa a si mesmo na necessidade de construir uma prática política que considere a imbricação dos sistemas de dominação como o seismo, racismo, heterosexismo e o capitalismo, porque considerar esta "matriz de dominacão" como bem denominou a afroamericana Hill Collins (Collins, 1999) é o que dá ao feminismo um sentido radical. 4
\end{abstract}

Portanto, urge a necessidade de uma análise feminista e crítica criminológica que esteja atenta aos lugares de poder ocupados por essas sujeitas criminalizadas, enquanto mulheres latino americanas, não brancas e pobres que não são contempladas pelo feminismo eurocentrado, branco e ocidental.

\title{
3 POR UMA CRIMINOLOGIA CRÍTICA FEMINISTA DECOLONIAL DIANTE DE UM DISCURSO UNIVERSAL DE DIREITOS HUMANOS
}

O Direito penal nesse quadro de proliferação de riscos, longe de atuar como instrumento de proteção da sociedade contra possíveis eventos catastróficos, continua mantendo a sua histórica função de gestão dos excedentes (CARVALHO, 2013b, p.194). A Política Criminal deve ser concebida como integrante de uma ampla política social.

Nesse sentido, rompe-se com as diretrizes da Criminologia Tradicional, e orienta-se com a finalidade de diagnosticar a situação pelo crivo da Criminologia Crítica, que analisa o delito tanto pela sua construção política, como por meio da atuação concreta do sistema penal e que define o resultado da aplicação da norma penal e as estatísticas criminais como produtos de conflitos sociais, lutas de classes, inerentes à sociedade capitalista, que visa expor as reais

\footnotetext{
4 La descolonización para nosotras se trata de una posición política que atraviesa el pensamiento y la acción individual y colectiva, nuestros imaginarios, nuestros cuerpos, nuestras sexualidades, nuestras formas de actuar y de ser en el mundo y que crea una especie de "cimarronaje" intelectual, de prácticas sociales y de la construcción de pensamiento propio de acuerdo a experiencias concretas. Se trata del cuestionamiento del sujeto único, al eurocentrismo, al occidentalismo, a la colonialidad del poder, al tiempo que reconoce propuestas como la hibridación, la polisemia, el pensamiento otro, subalterno y fronterizo. Estas propuestas críticas del feminismo latinoamericano y caribeño son posiciones de oposición al feminismo ilustrado, blanco, heterosexual, institucional y estatal, pero sobre todo un feminismo que se piensa y repiensa a sí mismo en la necesidad de construir una práctica política que considere la imbricación de los sistemas de dominación como el sexismo, racismo, heterosexismo y el capitalismo, porque considerar esta "matriz de dominación” como bien la denominó la afroamericna Hill Collins (Collins, 1999) es lo que da al feminismo un sentido radical (2009, p 03).
} 
funções exercidas pelo Direito Penal em contraposição com aquelas divulgadas pelo discurso oficial (CARVALHO, 2013b. p.194). De acordo com Vera Regina Pereira de Andrade (2006, p. 13):

\begin{abstract}
Evidentemente que um tal funcionamento interno do Sistema de Justiça Criminal e do controle social somente adquire sua significação plena quando reconduzido ao sistema social (à dimensão macrossociológica) e inserido nas estruturas profundas em ação que o condicionam, a saber, o capitalismo e o patriarcado, que ele expressa e contribui a reproduzir e relegitimar, aparecendo, desde sua gênese, como um controle seletivo classista e sexista ( ademais de racista), no qual a estrutura e o simbolismo de gênero operam desde as entranhas de sua estrutura conceitual, de seu saber legitimador, de suas instituições , a começar pela linguagem: eis o sentido da seletividade.
\end{abstract}

Diante da evidente omissão de gênero frente ao poder sancionador do Estado, tanto no campo criminológico quanto no jurídico-penal, onde a mulher, diante dessa abordagem, ocupa um papel completamente secundário, posto que um poder de punição que se apresenta como poder de criminalização e encarceramento, tende a desconsiderar um gênero que representa cerca de 5\% da população criminal (ZAFFARONI, 1995, p 24), a perspectiva da Criminologia Feminista é imprescindível visto que discute a inserção de categorias como patriarcado e gênero na esfera da justiça criminal. Concordamos com Vera Regina Pereira de Andrade:

\footnotetext{
a mulher torna-se vítima da violência institucional plurifacetada do sistema, que expressa e reproduz, por sua vez, dois grandes tipos de violência estrutural da sociedade: a violência das relações sociais capitalistas (a desigualdade de classe) e a violência das relações sociais patriarcais (traduzidas na desigualdade de gênero), recriando os estereótipos inerentes a essas duas formas de desigualdade (...) (ANDRADE, 2004, p. 265)
}

O direito penal não é, e não pode ser considerado um instrumento eficaz para a proteção das mulheres, posto que transporta e reproduz os valores da sociedade, marcada pelo patriarcalismo, que as discrimina e as trata como objeto pertencente aos homens (SILVA, 2012, p. 11-12). A criminologia feminista irrompe dentro de uma perspectiva já crítica e de viés emancipatório para denunciar a marginalização que a categoria gênero sofre mesmo nos espaços pretensamente contra-hegemônicos.

De acordo com o crivo da criminologia feminista, ao ingressar na criminalidade a mulher sai do que lugar que lhe destinaram, ela adentra o espaço público, abandona por meio de um ato de violência um estereótipo de exclusivamente vitimizada, sensível e pacata. A maternidade, por exemplo, foi bastante utilizada como medidor de 'normalidade', e como indica Lagarde (2003, p. 349), as mulheres formam "parte de uma história que as conformam como 
mãe e esposas, de maneira que a conjugalidade e a maternidade são esferas vitais que organizam os modos de vida feminino, independente da idade, da classe e da definição política ou religiosa." Ser mãe, neste contexto, é uma condição invariável para que as mulheres alcancem a 'congruência de gênero'. No começo do século XX, os crimes praticados por mulheres eram destacadamente restritos ao espaço privado e dificilmente detectáveis. (Soares \& Ilgenfritz, 2002).

Assim, o Direito Penal e o Sistema de Justiça Criminal são direcionados e criados para sujeitos masculinos criminalizados, tem base e fundamentos androcêntricos históricos, visto que aos homens sempre foram reservadas as esferas públicas da vida, o que inclui o crime. No entanto, é importante analisar sob que perspectiva feminista o Sistema de Justiça Criminal que criminaliza mulheres e não oferece suporte estrutural e institucional para recepcioná-las em seu objetivo divulgado no discurso oficial, é criticado. Ao passo que identificamos o fato de que o Sistema de Justiça Criminal nunca foi pensado para a realidade feminina, visto que às mulheres sempre foi destinado os âmbitos privados da vida social, e atribuídos a elas os esterótipos de inofensivas, puras, maternais, sensíveis, passivas e domésticas, devemos analisar se a todas as mulheres recai essa imagem construída historicamente, ou se estamos focando em apenas no perfil de um grupo de mulheres destituídas de uma imagem criminalizável ou reprovadas por si só no meio social.

É nítida a presença do sexismo nas instituições, a partir do momento em que há a discriminação e preconceitos dirigidos às mulheres de uma forma geral, no entanto, de acordo com alguns autores, pode-se dividir esse sexismo em duas modalidades; o sexismo que prejudica explicitamente a mulher e a hostiliza, e o sexismo paternalista que de certa forma forma é benevolente e retoricamente diz cuidar e proteger a mulher visto que ela seria "o sexo frágil". Ambos os sexismos trazem ideologicamente a crença na existência de um "destino fisiológico, psicológico e econômico para a mulher" (RIBEIRO, 2013, p. 506)

A imagem da mulher como mãe, esposa, frágil e restrita apenas ao âmbito privado não é uma caracterização que se conforme a realidade da mulher criminalizada na América Latina e especialmente no Brasil, visto que as mulheres encarceradas e alvos da Seletividade Penal, são em sua grande maioria as mulheres negras e moradoras das grandes periferias, e que possuem uma imagem e possibilidades de vida históricas diametralmente diversa da mulher branca e europeizada que possuía os papeis sociais atribuídos de fragilidade, castidade e destinada para a vida familiar somente. É preciso descolonizar as visões criminológicas feministas portanto, visto que elas trazem em seu arcabouço teórico uma referência 
eurocêntrica e branca muito forte e que não se alia a realidade da mulher tida como criminosa na América Latina, nesse sentido Ochy Curiel (2009, p. 07-08) acrescenta:

\begin{abstract}
Descolonizar para as feministas latinoamericanas e caribenhas supõe superar o binarismo entre teoria e prática pois lhe potencializaria para poder gerar teorizações distintas, particulares, significativas ao que se tem feito na região, que muito pode oferecer como aporte para descentralizar o sujeito eurocêntrico e a subalternidade que o mesmo feminismo latinoamericano reproduz em seu interior, senão seguiremos analisando nossas experiências com os olhos imperiais, com a consciência planetária de Europa e América do Norte que definem o resto do mundo como o OUTRO incivilizado e natural, irracional e não verdadeiro. Paralelamente, o desafio ético e político das feministas europeias e norteamericanas implicará reconhecer estas experiências teóricas e políticas como parte do acervo e da genealogia feminista, visto que apenas assim será possível um feminismo transnacional baseado na cumplicidade e solidariedade de muitas das feministas com as quais compartilhamos projetos políticos de emancipação. 5
\end{abstract}

Dessa forma é de imperativa relevância analisar a situação social e histórica da mulher criminalizada na América Latina e Brasil, majoritariamente punida pelos crimes relacionados às drogas, sob uma perspectiva contra-hegêmonica e não eurocêntrica. É necessário não silenciar as diferentes trajetórias e visibilizar os diferentes papeis sociais atribuídos a elas a fim de se fazer um diagnóstico que aponte para a emancipação dessas sujeitas. Como ilustrativo dessa diversidade, é interessante notar o seguinte apontamento feito sobre os esterótipos sociais relativos às mulheres brancas e às mulheres negras e pardas (que conforme já citado anteriormente, compõem a maior parte das encarceradas pelo Sistema de Justiça Criminal), Djamila Ribeiro (2005) aponta:

\begin{abstract}
Mulheres negras não foram aquelas que ficavam em casa enquanto o marido trabalhava: desde o pós-abolição, em sua maioria, são aquelas responsáveis por suas famílias. Por conta das violências pelas quais passam, criou-se o mito da mulher negra forte, guerreira, que enfrenta tudo. Mulheres negras precisam ser fortes porque o Estado é omisso. Essa denominação, além de encobrir a omissão e ilegalidade do Estado, também é desumana no sentido de não reconhecer suas fragilidades próprias da condição humana. Como diz Grada Kilomba, mulheres negras são o outro do outro por serem a dupla de antítese de branquititude e masculinidade, o que cria uma hierarquização de humanidade, nos colocando numa sub-categoria.
\end{abstract}

5 Descolonizar para las feministas latinoamericanas y caribeñas supondrá superar el binarismo entre teoría y práctica pues le potenciaría para poder generar teorizaciones distintas, particulares, significativas que se han hecho en la región, que mucho puede aportar a realmente descentrar el sujeto euronorcéntrico y la subalternidad que el mismo feminismo latinoamericano reproduce en su interior, sino seguiremos analizando nuestras experiencias con los ojos imperiales, con la conciencia planetaria de Europea y Norteamericana que definen al resto del mundo como lo OTRO incivilizado y natural, irracional y no verdadero. Paralelamente el reto ético y político de las feministas europeas y norteamericanas implicará reconocer estas experiencias teóricas y políticas como parte del acervo y la genealogía feminista, pues solo así será posible un feminismo transnacional basado en la complicidad y solidaridad de muchas de las feministas que compartimos los mismos proyectos políticos de emancipación (2009, pp. 07-08). 
Portanto, é importante notar que as mulheres latino americanas, em especial, as negras que foram trazidas nos processos de colonização, tiveram uma outra relação com a dicotomia gênero feminino - esfera privada e gênero masculino - esfera pública, visto que historicamente, mesmo ainda sendo responsáveis pelas atividades domésticas de seus lares familiares, ainda tinham que atuar no espaço público e em espaços privados alheios, devido a necessidade de saírem de suas casas para trabalhar fora em funções precárias e informais, como domésticas, prostitutas, vendedoras e etc, essas não usufruíam do espaço público de uma forma reconhecida e legitimada, com uma participação política anulada e totalmente invisibilizadas como sujeitas de direitos.

Nesse sentido, de acordo com o Relatório da Comissão Externa de Feminização da Pobreza, no caso das mulheres negras é de $71 \%$ a proporção entre elas das que trabalham em ocupações precárias e $41 \%$ delas se concentram nas ocupações mais precárias e desprotegidas do mercado de trabalho (OIT). A tendência maior da mão de obra feminina ao desemprego é acentuada por variáveis de raça. A mulher negra apresenta uma desvantagem marcante neste aspecto, com 13,6 \% de desemprego, em relação aos 10\% das mulheres brancas. Essa desvantagem se agudiza no caso das mulheres jovens negras, que apresentam taxas alarmantes de desemprego de $25 \%$. Além disso, no que se refere ao emprego doméstico, as mulheres negras são maioria. Por essas razões, alcançam somente $39 \%$ dos rendimentos dos homens brancos

Silva (2013) em pesquisa sobre a violência sexual contra as mulheres e a percepção delas sobre o fenômeno, analisou que:

Considerando a frequência das respostas da subcategoria Ingenuidade, pôdese reafirmar a visão da mulher branca como um ser frágil e ingênuo, contrapondose à ideia da negra hipersexualizada, o que pode ter contribuído para a indignação identificada nas respostas para a objetificação da branca e maior aceitação desta mesma objetificação quando referente à mulher negra (SILVA, 2013, p. 10).

Portanto, a situação da mulher latino americana criminalizada, majoritariamente negras e pobres, não pode ser analisada mediante uma ótica feminista que desconsidere uma construção histórica diferenciada, que para além das desigualdades entre as relações de gênero se baseou na exploração colonialista, racista, patrimonialista e estruturalmente excludente.

De acordo com a feminista latinoamericana Alba Carosio, a feminização da pobreza tem dado lugar a feminização da sobrevivência. A necessidade de simplesmente sobreviver fez surgir o modelo das trabalhadoras "genéricas" (flexíveis, com capacidade de adaptação a 
horários e a distintas tarefas, substituíveis por outras que aceitem a mesmas condições de superexploração). Migração laboral, tráfico de drogas e prostituição são, cada vez mais, saídas forçadas para a sobrevivência de milhões de mulheres ${ }^{\mathrm{i}}$. O mercado clandestino de entorpecentes, retroalimentado pelo proibicionismo, se aproveita do papel social que a mulher carrega, em sua grande maioria, não-branca, chefe de família, moradora da periferia, e agrava sua situação de vulnerabilidade.

O Estado que vem adotando medidas de austeridade e reajuste dos direitos sociais, junto das medidas neoliberais e neodesenvolvimentistas implantadas em vários países da América Latina acaba por expandir o trabalho invisível feito pelas mulheres no espaço privado, pois por promover a retirada das garantias e direitos sociais, acaba por sobrecarregar as mulheres com tarefas domésticas que poderiam ser supridas por serviços públicos de qualidade, como saneamento básico, saúde e educação resultando no aumento do trabalho gratuito da mulher em casa, ampliando o seu nível de precarização e vulnerabilidade social.

Essa realidade demonstra que tal situação pode favorecer o cometimento de ilícitos, devido a falta de trabalho e inserção no mundo dos empregos formais, a mulher negra é empurrada para a prática de delitos, e após ser criminalizada a sua vulnerabilidade social apenas aumenta.

Dados de 2012 do Ministério da Justiça, apontam que 49\% das presas têm entre 18 e 29 anos, 39\% têm entre 30 e 45 anos e 12\% têm mais de 46. Em relação à escolaridade, 44\% declararam ter o ensino fundamental incompleto e apenas $3 \%$ chegaram a ingressar em uma universidade. As negras e pardas são maioria dentro das unidades prisionais do País e somam $61 \%$ das detentas. Nesse contexto surge o fato de que o crime que mais encarcera mulheres na América Latina é o tráfico de drogas, entre essas mulheres encarceradas, a grande maioria é de não-brancas, ou seja, negras e pardas, com baixa escolaridade, além de serem mães, como já demonstrado em dados anteriormente citados.

De acordo com Luciana Chernicharo (2014, p. 103), o encarceramento feminino e os dados quantitativos permitem afirmar que:

i) as mulheres seguem sendo minoria em relação à população carcerária total, isto é, representam cerca de 2 a $9 \%$ da população presidiária dos 222 países consultados pelo ICPS em 2013. O mesmo se verifica no Brasil, onde a população feminina de presas representa $6,6 \%$ da população total; ii) a partir dos anos 90 , houve um incremento da população feminina na América Latina, principalmente por crimes relacionados às drogas; iii) no Brasil, este incremento parece corroborar com as tendências mundiais, e os dados do Depen indicam que 60\% da mulheres estão presas por delitos relacionados às drogas; e iv) o perfil das mulheres nas cadeias brasileiras é bastante parecido com o perfil de mulheres presas em outros países da América Latina, em sua maioria jovem, com pouco estudo formal e com histórias de violência de gênero e exclusão social. 
Assim, qualquer teoria criminológica pretensamente crítica e feminista que analise a política criminal para as mulheres na América Latina e Brasil e não se despoje dos valores e moldes eurocêntricos e brancos desconsiderando a realidade diferenciada aqui presente não conseguirá explicar a totalidade desse fenômeno ou oferecer respostas satisfatórias.

\section{CONCLUSÃO}

As teorias decoloniais vêm exercendo uma grande influência na produção de conhecimento, o que deve ser inserido também na Teoria dos Direitos Humanos. Nesse diapasão, a discussão acerca do feminismo tem sido fortemente impactada visto que nesses processos de transculturação e reconfiguração de fronteiras tem sido criada abertura para revisar o lugar e a prática das mulheres envolvidas nesses processos. A partir do reconhecimento da incompletude de qualquer perspectiva analítica teórica focada no eixo dicotômico, países colonizadores - centro e países colonizados - perifeira, que vise a abordagem dos processos e fenômenos sociais latinoamericanos, surge a necessidade de uma reformulação epistemológica que levem em conta os elementos constitutivos da nossa realidade global. Nesse sentido, para a análise da relação entre gênero e política criminal na América Latina, conceitos como colonização, capitalismo, classe, raça e etnia devem ser revisitados e elevados a categoriais fundamentais de estudo.

Enquanto isso, a Guerra às Drogas segue como a maior causa de encarceramento e criminalização de mulheres no Brasil e América Latina, como já visto anteriormente, a grande maioria dessas mulheres são negras, moradoras de regiões periféricas dos grandes centros urbanos, com baixa escolaridade e chefes de família, em meio a essa realidade, é imperativa a análise desse fenômeno sob a ótica de um feminismo que discuta as peculiaridades das mulheres latino americanas que são selecionadas pelo Sistema de Justiça Criminal. O feminismo hegêmonico de bases históricas brancas e europeias, como base epistemológica para uma criminologia feminista, não fornece respostas que abarquem os modos de vidas e as experiências dessas sujeitas criminalizadas.

Assim, com o objetivo de inteferir nas estruturas das desigualdades é fundamental subverter as lógicas ocidentais mantenedoras das relações de poder, como discutir a colonialidade de gênero, e redefinir linguagens epistêmicas, e a produção de novos saberes e formas de produção de conhecimentos, fazendo ecoar as práticas decoloniais para que a partir 
desse coro de vozes coletivas e marginalizadas possamos construir um feminismo próprio latinoamericano, que descolonize os discursos, e que possa ser essencial na análise criminológica feminista na América Latina. Diante dessas questões, restam as rupturas no discurso clássico dos direitos humanos, que representam possibilidades de reformulação das bases de um discurso absoluto, universal e ocidental. Nesse sentido, é necessária a utilização dessas fissuras para se problematizar o termo clássico/corrente "direitos humanos", pois esse abriga o discurso supra-histórico de convergência, cristalizando padrões valorativos absolutos e universais, sendo limitador, quando não colonizador, em contextos específicos, como o caso das mulheres em crimes relacionados à drogas na América Latina.

\section{REFERÊNCIAS}

ABREU, Haroldo. Para além dos direitos. Cidadania e hegemonia no mundo moderno. Rio de Janeiro: Editora UFRJ, 2008.

ALVES, José Augusto Lindgren. Os Direitos Humanos na pós-modernidade. São Paulo: Perspectiva, 2013.

ANDRADE, Vera Regina Pereira de. A soberania patrarcal: o sistema de justiça criminal no tratamento da violência sexual contra a mulher. Revista Brasileira de Ciências Criminais, n 48, maio/junho, 2004, pp. 260/290.

Pelas mãos da criminologia: o controle penal para além da (des)ilusão. Rio de Janeiro: Revan; 2012.

ATIENZA, Manuel. Marxismos y Derechos Humanos. In: FEITOSA, Enoque; FREITAS, Lorena. (Orgs.). Marxismo, Realismo e Direitos Humanos. João Pessoa: Editora Universitária da UFPB, 2012.

BLOCH, Ernst. Derecho natural e dignidad humana. Trad.: Felipe Gonzalez Vincen. Madrid: Dykinson, 2011.

CARVALHO, Salo de. Antimanual de Criminologia. 5 ed. São Paulo: Saraiva, 2013.

CHERNICHARO, Luciana Peluzio. Sobre Mulheres e Prisões: Seletividade de Gênero e Crime de Tráfico de Drogas no Brasil. 2014. 160 f. Dissertação (Mestrado em Direito). Universidade Federal do Rio de Janeiro. Rio de Janeiro. 
CURIEL, Ochy. Descolonizando o feminismo: uma perspectiva desde America Latina y el Caribe. 2009.

GIACOMELLO, Corina. (2013b). Género, drogas y prisióne: experiencias de mujeres privadas de su libertad en México. México: Tirant lo Blanch.

GUEDES, M. A. (2006) Intervenções psicossociais no sistema carcerário feminino. Psicologia ciência e profissão.

HUNT, Lynn. A invenção dos Direitos Humanos: uma história. Tradução: Rosaura Eichenberg. São Paulo: Companhia das Letras, 2009.

LAFER, Celso. A Reconstrução dos Direitos Humanos: um diálogo com o pensamento de Hannah Arendt. São Paulo: Companhia das Letras, 1988.

LAGARDE, Marcela. (2003). Los cautiverios de las mujeres: madreesposas, monjas, putas, presas y locas. México: UNAM. p. 349.

MAIEROVICH, Walter Fanganiello. Nova Ameaça Amazônica. Carta Capital, 9.11.05, p. 23.

MILLAN, M. Feminismos, postcolonialidad, descolonización: Del centro a lós márgenes? Andamios, v. 8, n. 17, p. 11-36, 2011.

MOKI, M. P.(2005) Representações sociais do trabalho carcerário feminino. Dissertação de Mestrado Não- Publicada, Curso de Pós-Graduação em Ciências Sociais, Universidade Federal de São Carlos, São Paulo.

OLIVEIRA, Luciano. Os Excluídos Existem? Notas sobre a elaboração de um novo conceito. In: Revista Brasileira de Ciências Sociais, n. 33, fev. 1997, p. 49-61.

QUIJANO, Anibal. 2000. "Colonialidad del Poder, Eurocentrsismo y América latina", en: La Colonialidad del Saber: Eurocentrismo y Ciencias Sociales. E. Lander Comp. CLACSO. UNESCO. p. 217.

RIBEIRO, Djamila. Disponível em <http://www.geledes.org.br/feminismo-negro-violenciashistoricas-e-simbolicas/\#ixzz3kbMBABE7> acessado em 02/09/2015.

RIBEIRO, D. Para além da biologia: Beauvoir e a refutação do sexismo biológico. Sapere Aude, Belo Horizonte, v. 4, n. 7, p. 506-509, 1 sem. 2013.

SILVA, Natiene Ramos Ferreira da. Representações da Culpabilização de Mulheres Vítimas de Estupro: Uma Análise Étnico-Racial. Disponível Em: <http://estatico.cnpq.br/portal/premios/2013/ig/pdf/ganhadores_9edicao/Cat_E_Graduacao/N atieneRamos.pdf >. Acessado em 03.09.2015

SANTOS, B. S.; MENESES, M. P. (Org.). Epistemologias do Sul. São Paulo: Cortez, 2010. $637 \mathrm{p}$. 
SILVA, Lillian Ponchio e. Sistema Penal: campo eficaz para a proteção das mulheres. In: BORGES, Paulo César Corrêa (org.). Sistema Penal e Gênero: tópicos para emancipação feminina. São Paulo: Cultura Acadêmica, 2012. p. 11-27.

VILLEY, Michel. O Direito e os Direitos Humanos. Tradução: Maria Ermanita de Almeida Prado Galvao. Martins Fontes, 2007.

ZAFFARONI, Eugênio Raul. A mulher e o poder punitivo. In: Mulheres: vigiadas e castigadas. São Paulo: CLADEM Brasil, 1995, pp. 23-39. 